\title{
Passion Play: The Relationship between Passion and Motivation in On-Line Gaming
}

\author{
Ralf Greenwald $^{1^{*}}$ and Charissa Blackmore ${ }^{1}$ \\ Central Washington University, Ellensburg, WA
}

Received: November 23, 2017; Accepted: December 17, 2017; Published: December 19, 2017

*Corresponding author: Ralf Greenwald, Psychology Department, Central Washington University, Ellensburg, Washington, USA, E-mail: greenwar@cwu.edu

\begin{abstract}
The study examined the relationship between massively multiplayer online role-playing game (MMORPG) users' motivations for playing and obsessive and harmonious passion. In the current study, data was gathered from 136 participants using the Passion Scale and the Users' Experience Measurement in MMORPGs Questionnaire. Results showed that obsessive passion had a positive correlation with role play, challenge, competition, and fantasy. Further, harmonious passion was found to have significant positive relationships with all motivation factors except for competition. Clinical implications of the study may indicate that in dealing with patients who suffer from compulsive gaming, focusing on ways to meet psychological needs in the real world instead of through on-line gaming, via emphasis on need satisfaction may provide a helpful intervention method.
\end{abstract}

Keywords: MMORPG; On-Line Gaming; Passion; Motivation; Gaming Addiction

\section{Introduction}

Since the release of the first massively multiplayer online role-playing game (MMORPG) in the late 1990s, the popularity of these games has exploded across the world [1]. In essence, an MMORPG is an online game where players from all over the world can interact and play together in a virtual and dynamic environment that evolves with the players [2]. The online format's emphasis on player interaction and cooperation led to a new kind of gaming: one filled with potential rewards, role playing, and the opportunity for social interactions that might otherwise be inaccessible to players. Although gaming has been thought of by many as primarily directed at children, research has shown that this is no longer the case. Specifically, a study of over 900 MMORPG players, the mean player age was found to be 23.6 [3]. Additionally, the number of people who play online has steadily increased [4]. For instance, World of Warcraft (wow), one of the largest and most popular MMORPGs available, reported reaching 12 million subscribers in 2010 [5].

Although the prevalence of online communication and innovative gaming may come with potential benefits, it may also put heavy users at risk for developing addictive tendencies. Past studies in this area have tended to focus on identifying potential negative side effects of heavy video game and internet usage, but recently research has begun to focus on other potential areas of interest, such as players' motivations for playing [6]. The following sections will outline some of the key aspects involving the relationship of motivation and passion of MMORPG players. Specifically, research on gaming addiction, motivations for playing and personality traits, and passion for gaming will be covered.

\section{Gaming Addiction}

In recent years, researchers have been interested in exploring the potential for online gaming addiction and have related it to gambling addiction, which is the only addictive disorder included in the DSM-5 that is not substance-related [7]. For instance, Hussain, Griffiths, and Baguley (2012) sought to examine the pervasiveness of MMORPG addiction. To do so, they administered an online questionnaire to 1420 participants who self-identified as gamers. In addition to gathering information on demographics and online habits, researchers incorporated seven items representing seven DSM-based criteria for game addiction into the survey. Researchers found that women tend to play MMORPGs about as often as men do, although it was hypothesized that they may be drawn to them for different motivational reasons. Hussain et al. recommended that future research should examine differences between both gender game-type preferences and motivations for playing. Interestingly, the researchers found a positive correlation between addictive behaviors, the number of times a week spent playing, and the amount of time spent playing per session. At the same time, they found both a negative relationship between the number of times played per week and the age of the gamer and a positive relationship between how long a playing session lasted and the player's age.

Similarly, a study conducted by Shang et al. Aimed to expand the understanding of MMORG addiction in relation to other lifestyle factors, with an emphasis on the user's experience within the game[7,8]. The study began by identifying both personal and social factors that have been shown to be related to potential addiction: curiosity, fantasy, control, reward, challenge, cooperation, recognition, competition, obligation, and belonging. An additional factor included was role-playing. Data were gathered using an online self-report questionnaire that focused on personal and social factors and an addiction rating scale. Results showed that male students spent significantly more time playing daily; however, no gender differences in weekly playing 
or addiction levels were observed. It was found that reward, role-playing, curiosity, obligation, and belonging were shown to be significant factors that predicted addiction. Additionally, the data supported the hypothesis that a positive correlation exists between addiction levels and amount of time spent playing the game.

\section{Motivations for Playing and Personality Traits}

Past researchers have found that the majority of game players form friendships in massively multiplayer online games (MMOS). Players often refer to MMOS as social and cite the communities as part of the draw [9]. Generally, when the phrase "social" is used in the context of gaming, it is referring to group interactions, direct communication, and playing the game with other users. However, researchers note that there are other draws to the social, multiplayer nature of MMOS [10].

MMO character progression, item collection, and the community of other players provide a way for these achievements to be recognized. Although the motivating factor is achievementoriented in this context, the social nature of MMOS is necessary in order to provide an audience for the player. Even players who are not motivated by having their achievements and status being recognized by others in the game can still be drawn to the social nature of MMOS. Although many players spend a significant amount of time playing alone, the fact that they play alone in a populated world presents a different experience than a singleplayer game. Even if a user chooses not to interact, sharing game space with others and having the option to interact makes a difference in the level of immersion the game world presents [11].

Graham and Gosling investigated the relationship between motivations for playing and personality traits according to the Big Five (i.e., neuroticism, extraversion, openness to experience, conscientiousness, and agreeableness) [19]. Researchers administered an online survey to participants who played World of Warcraft. The motivation factors used in their comparison were social, achievement, immersion, leadership, and independence. Results showed that participants who scored highly on the social motivation tended to score higher on extraversion, neuroticism, openness and agreeableness. Achievement motivation was also negatively correlated with conscientiousness, agreeableness, and openness, while leadership was positively associated with extraversion, conscientiousness, and openness. Lastly, players who scored high on the immersion motivation tended to score highly on openness, neuroticism, and agreeableness. Other studies have reported similar results in that they found a significant relationship between online gaming addiction and several personality traits $[12,19]$.

Smahel, Blinka, and Ledabyl focused their research on whether not identification with an avatar - a player-created character used to navigate the world in an MMORPG - and role-playing tendencies was predictive of addiction. Researchers collected online survey data from participants who were divided into several age groups [13]. The questionnaire used included items that related to both MMORPG addiction and the player's relationship with an avatar or character. Researchers found that the amount of time spent playing MMORPGs strongly correlated with addiction; additionally, younger participants were more likely to display addictive tendencies. An "identification" score was created using questions related to their relationship to their avatar, and scores for this factor were found to be both higher in younger participants and positively correlated with addiction.

The three primary components of motivation that have been identified by researchers are social, achievement and immersion [14]. The social dimension is defined as playing in order to interact socially with other players. The achievement dimension is characterized by engaging in MMORPG use in order to accomplish goals and earn achievements. Lastly, the immersion dimension represents users playing MMORPGs primarily to explore and immerse themselves in the MMORPG environment. In regards to MMOS, many of the elements that researchers have focused on linking to predicting addiction have fallen into these categories: for example, Smahel's focus on "avatar identification" would fall under the category of immersion [13].

Other researchers have drawn similar conclusions regarding the importance of the immersion motivation when it comes to addiction: Kirby, Jones, and Copello found that there was a negative relationship between amount of hours spent playing and psychological wellbeing, but only when a mediating "immersion" motivation was involved. At the same time, research has shown that context is an important mediating factor $[14,15]$. Players who have ample amounts of free time due to living circumstances may not exhibit addictive characteristics and that "a person can excessively play without necessarily being addicted" [14]. It is therefore important to identify other factors related to gaming and player characteristics that could be predictive of addiction. The following section will cover research focusing on passion and its relation to gaming.

\section{Passion and Gaming}

Passion, according to researcher Richard Vallerand, is a concept that has not been explored in depth outside of a romantic context. Vallerand describes passion as "a strong inclination toward a self-defining activity that one likes" where the activity becomes central to how someone defines his or her identity [16]. In other words, when an activity is something we are passionate about, it becomes incorporated into how we view ourselves and how we describe ourselves to others. Someone who is passionate about writing becomes a "writer" and someone who is passionate about video games becomes a "gamer." Moreover, Vallerand expands upon passion by describing the concept of a "dualistic model of passion" [16]. Specifically, Vallerand's research and development of the Passion Scale supported the conclusion that harmonious and obsessive passions were two separate constructs. Obsessive passion involves the "controlled internalization of the activity into one's identity"; this involves internalizing the rules, standards and values that are related to the activity and not just the activity itself [16]. The internalization of the passionate activity is described as controlled, because it is generally linked to outside factors such as feelings of selfesteem, self-efficacy, and social recognition, and acceptance. 
Therefore, a person with obsessive passion engages in an activity not only because he or she is passionate about it, but also because other feelings are contingent upon doing so. A person who is harmoniously passionate about an activity recognizes the importance of the activity and chooses to freely engage in it. Unlike harmonious passion, obsessive passion leads to compulsion; as Vallerand states, it leads to "experiencing an uncontrollable urge to partake in the activity they view as important and enjoyable [16]." Vallerand went on to hypothesize that obsessive passion would correlate with maladaptive outcomes and that, although both forms of passion may lead to high levels of performance, obsessive passion would lead to higher levels of psychological distress in other areas of life (e.g., interference with social or work life).

Due to the compulsive urges associated with obsessive passion, it is more likely to lead to negative outcomes $[16,17]$ For example, a person who is obsessively passionate over gaming is likely to ruminate over a lost opportunity to play, whereas someone who is harmoniously passionate will not. Although both passionate people may engage in the activity for similar amounts of time if given the opportunity, obsessive passion may lead to an inability to properly focus on other areas of life due to distraction or resentment over the lost opportunity if they are prevented in engaging in the activity they are passionate about.

Currently, few studies have focused on passion in the context of gaming [18]. Using Vallerand's model of passion, researchers tested the relationship between harmonious passion (HP) and obsessive passion (OP) and internet addiction [18]. Results showed that OP positively correlated with computer usage, whereas HP did not. These findings supported that obsessive and harmonious passion represented separate constructs with different predictive outcomes in relation to online gaming. Additional studies have found that both HP and OP correlate with positive effect, whereas only obsessive passion correlated with negative affect $[17,20]$. Researchers also found that harmonious passion had a positive association with psychological health, selfrealization and life satisfaction, whereas obsessive passion did not [21].

Expanding on Vallerand's work, Przybylski, Weinstein, Ryan, and Rigby surveyed participants recruited from an online community in order to explore the relationship between a variety of factors including, need satisfaction, harmonious and obsessive passion, and play time [16,22]. Results showed that harmonious passion for gaming had a positive correlation with high levels of need satisfaction, whereas obsessive passion was correlated with low levels of the same. Harmonious passion was characterized by want, while obsessive passion was characterized by need. Additionally, harmonious passion positively correlated with psychological health, life satisfaction, and enjoyment of the game.

Furthermore, Utz, Jonas, and Tonkkens further explored the relationship between passion for MMORPGs and its effects on interpersonal relationships [23]. Researchers gathered demographic information and conducted an online survey that included Vallerand's (2008) Passion Scale. Results showed that the amount of time spent gaming had a negative effect on players only when their desire to play felt uncontrollable. Utz et al. concluded that obsessive passion and harmonious passion had different levels of predictive power regarding the negative effects of gaming, even though both constructs positively correlated with the amount of time spent playing MMORPGs.

More recently, researchers conducted a study that analyzed the relationship between passion and motivation regarding MMORPGs [24]. Using the Massively Multiplayer Online Games Motivation Scale (MMO-MS), researchers measured users' motivations in four different dimensions: achievement, social, exploration, and dissociation. It was found that HP and OP both predicted high levels of achievement and socialization motivations; in contrast, the exploration motivation was related to HP and dissociation was related to OP. The results of this study are limited due to the fact that females were excluded from the analysis. The exclusion of female participants is significant due to the fact that previous research has found gender differences in motivation for playing. For example, Poels, De Cock, and Malliet (2012) found that masculine traits positively correlated with having an achievement motivation, and that feminine traits positively correlated with social motivations for playing. Additionally, Poels et al. Also found that masculinity was positively related to social motivations in terms of teamwork, but not in terms of individual social relationships [8].

\section{The Present Study}

Considering that previous research has identified several distinct factors that correlate with the potential for MMORPG addiction, the current study aimed to explore the relationship between passion, gender, and motivations for playing. Specifically, the focus of this study was to investigate the possible relationship between motivations for playing MMORPGs and harmonious and obsessive passion. The present study expands the work of Fuster et al. (2014) through the inclusion of female participants and English speakers. Previous research has shown that HP was positively related to exploration, socialization, and achievement, and unrelated to dissociation, while OP was related to dissociation and achievement [24]. Additionally, past research found that curiosity, role-playing, belonging, obligation and reward were positively related to MMORPG addiction [7]. Given these findings, the current study hypothesized that obsessive passion would be positively related to curiosity, role-playing, belonging, obligation and reward.

\section{Method}

\section{Participants}

The current study used data from 143 participants recruited through forums affiliated with several MMORPGs. Six participant scores were excluded due to missing data (failure to complete both surveys) and one participant was excluded due to extreme outlier scores. Out of the 136 participants included in the analysis, $80.1 \%(n=109)$ were male and $19.9 \%(n=27)$ were female. The average age of participants was 26.15 years. All procedures were approved by the university Human Subjects Review Committee. 


\section{Materials}

In order to measure user types of motivation, the 'Users' experience measurement in MMORPGs' questionnaire was used. This measure was created by Shang et al. (2009) in order to identify experience factors that predicted motivation to play MMORPGs. There are a total of 44 items and 11 subscales. Each item consists of a statement (e.g., This game is novel and unique.) and the participant is asked to rate it on a five-point Likert scale ranging from strongly disagree to strongly agree. Shang et al. conducted a factor analysis to check for validity of the scale, in addition to using Cronbach's alpha to check for the internal reliability of the questions. They found that Cronbach's alpha was 0.93 and that each individual factor had a value that was at least 0.5 (2009).

Users' experiences as motivations for playing include 11 independent variables: challenge, fantasy, curiosity, control, roleplay, competition, cooperation, recognition, belonging, obligation, and reward. Challenge is described as the match between the game's difficulty level and the player's ability to overcome the game's challenges [8]. Fantasy involves drawing the user into an imaginative world that players would be unable to experience outside the game. Curiosity targets pleasure we obtain from our senses, in addition to encompassing a player's urge to explore, discover surprises, and learn more about the game. Control relates to feelings of self-efficacy and accomplishment, primarily through feeling in control of the game itself (i.e., the user interface and achievements within the game). Role-play involves the identification with an in-game avatar or character, and the competition factor is defined by competition with other users through in-game contests and scores. Cooperation focuses on how players work together to accomplish goals within the game, usually by forming parties or groups. Recognition as a motivating factor emphasizes in-game achievements being recognized and available for others in the game to see and gives the player a sense of accomplishment. The belonging factor involves the player feeling like a part of a community within the game, usually in the form of a guild. Obligation involves the feelings of responsibility that come with being a part of an in-game community, being needed, and feeling the need to contribute. Lastly, reward involves in-game activity being positively reinforced via the acquisition of items or in-game currency. The Passion Scale, as developed by Vallerand et al. (2003), was administered in order to measure harmonious and obsessive passion. This scale has a total of 14 items divided into two subscales, each consisting of seven items. Items consist of statements such as 'I cannot live without it' and participants are asked to rate them on a 7-point Likert scale. Researchers ran a confirmatory factor analysis and found that the data fit well and were reliable; the correlation between harmonious and obsessive passion was .46 [25].

\section{Procedures}

Participants were recruited through advertisements posted on online forums associated with popular MMORPGs, including http://www.MMORPG.com/ and a subreddit dedicated to female gamers. The survey was also advertised in subreddits dedicated to specific MMORPGs, including World of Warcraft, Lord of the Rings Online, Elderscrolls Online, and Guild Wars 2. Participants were directed to the online survey which was administered through Qualtrics. After consenting to the study, participants first filled out a short demographics survey. Following the completion of the demographics section, participants completed two scales: The Passion Scale, as developed by Vallerand et al., and the Users' experience measurement in MMORPGs scale, as developed and used by Shang et al. After the completion of the survey, participants were instructed to clear their cache and browsing history.

\section{Results}

Table 1 shows the participant background data indicating that the sample mainly consisted of primarily white (88.24\%) male (80.15\%) English-speakers with a mean age of 26.15 $(\mathrm{n}=134)$. A Pearson's product-moment correlation was conducted to determine the relationships between harmonious and obsessive passion and 11 motivational variables. Scores were approximately normally distributed for all 11 motivational variables, as evidenced by viewing Q-Q Plots. Additionally, skewness and kurtosis for the 11 motivational variables were all within an acceptable range for normal distribution (z-scores \pm 2.58 ). Harmonious passion scores were normally distributed with a skewness of $0.093(\mathrm{SE}=0.207$ ) and a kurtosis of -0.402 (SE $=0.411$ ). Obsessive passion scores had a skewness of 0.545 (SE $=0.209$ ) which indicate a positive skew and a kurtosis of -0.548 $(\mathrm{SE}=.416) .[$ Table 1]

\begin{tabular}{|c|c|c|}
\hline \multirow{2}{*}{ Gender n (\%) } & Women & 27 (19.9\%) \\
\hline & Men & $109(80.1 \%)$ \\
\hline Age & M (SD) (min-max) & $26.15(7.75)(18-60)$ \\
\hline \multirow{4}{*}{$\begin{array}{l}\text { Ethnicity n } \\
\text { (\%) }\end{array}$} & Asian or Asian American & $11(8 \%)$ \\
\hline & Hispanic or Latino & $3(2.2 \%)$ \\
\hline & White & $120(87.0 \%)$ \\
\hline & Multiracial & $2(1.4 \%)$ \\
\hline \multirow{9}{*}{$\begin{array}{l}\text { Employment } \\
\text { status n (\%) }\end{array}$} & Employed full-time & $54(39.1 \%)$ \\
\hline & Employed part-time & $15(10.9 \%)$ \\
\hline & Out of work and looking & $14(10.1 \%)$ \\
\hline & Out of work, not looking & $2(1.4 \%)$ \\
\hline & Homemaker & $1(0.7 \%)$ \\
\hline & Student & $48(34.8 \%)$ \\
\hline & Unable to work & $3(2.2 \%)$ \\
\hline & $0-10$ & $26(18.8 \%)$ \\
\hline & $11-20$ & $46(33.3 \%)$ \\
\hline \multirow{5}{*}{$\begin{array}{l}\text { Hours played } \\
\text { per Week n } \\
(\%)\end{array}$} & $21-30$ & $27(19.6 \%)$ \\
\hline & $31-40$ & $18(13 \%)$ \\
\hline & $41-50$ & $10(7.2 \%)$ \\
\hline & $50+$ & $10(7.2 \%)$ \\
\hline & Age first began playing & $15.97(6.38)(7-42)$ \\
\hline
\end{tabular}


Table 2 displays the means, standard deviations, and inters correlations of the measures. Harmonious passion (HP) had a small positive correlation with challenge $(\mathrm{r}=.244, \mathrm{p}<.01)$, control $(\mathrm{r}=.222, \mathrm{p}<.01)$, cooperation, $(\mathrm{r}=.261, \mathrm{p}<.01)$, belonging $(\mathrm{r}=$ $.290, \mathrm{p}<.01)$, and obligation $(\mathrm{r}=.293, \mathrm{p}<.01)$, and a moderate positive correlation with rewards $(\mathrm{r}=.351 \mathrm{p}<.0005)$, fantasy $(\mathrm{r}$ $=.385, \mathrm{p}<.0005)$, curiosity $(\mathrm{r}=.398, \mathrm{p}<.0005)$, role play $(\mathrm{r}=$ $\left..380^{* *}, \mathrm{p}<.0005\right)$, and recognition ( $\left.\mathrm{r}=.420, \mathrm{p}<.005\right)$. Obsessive passion (OP) was shown to have a moderate positive relationship with role play $(\mathrm{r}=.360, \mathrm{p}<.0005)$ and weak positive relationships with challenge $(\mathrm{r}=.171, \mathrm{p}<.05)$, competition $(\mathrm{r}=.245, \mathrm{p}<.01)$, and fantasy $(r=0.221, p<.05)$. OP had no significant relationship with curiosity $(r=-.011)$, reward $(r=0.053)$, obligation $(r=$ 0.105), or belonging $(r=.065)$. [Table 2]

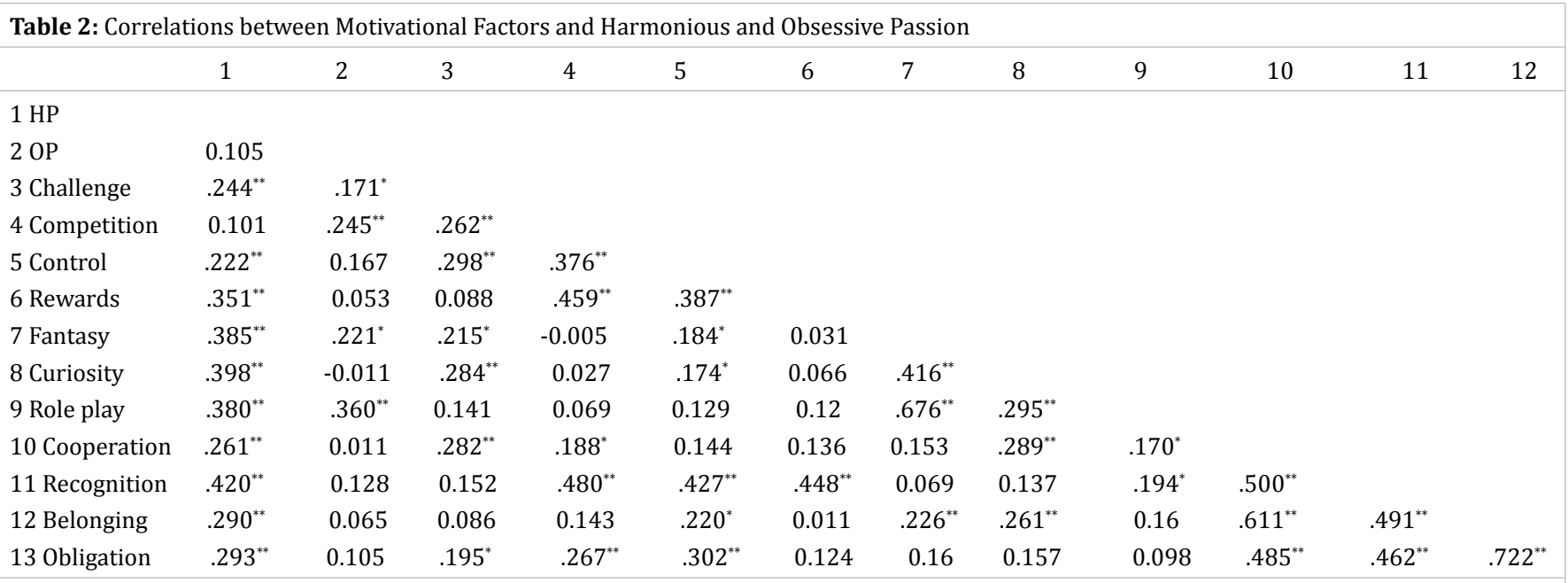

Note $^{*}=$ statistically significant at the $\mathrm{p}<.05$ level. ${ }^{* *}=$ statistically significant at the $\mathrm{p}<.01$ level $(2$-tailed $)$

\section{Discussion}

The results of the present study indicate that obsessive passion (OP) was most strongly related to the role-play motivation. OP was also found to have weak positive relationships with fantasy, competition and challenge. OP was not found to have significant relationships with the remaining four motivations (reward, curiosity, obligation, and belonging) contrary to the predictions of the hypothesis. However, harmonious passion (HP) was found to have significant positive relationships with all motivation factors except for competition. The relationships between HP and motivational factors are similar to the results of past research regarding passion, which have linked HP to social, achievement, and immersion dimensions of motivation. However, the findings regarding OP conflicted with the results of Shang et al. (2009), who found positive correlations between scores on an addiction measure and reward, role-playing, curiosity, obligation and belonging motivations.

Considering the present study's hypothesis was influenced by the findings of Shang et al. (2009), it is important to identity possible reasons for these differences. Two potential reasons may include differences in population and differences between obsessive passion and addiction. First, participants from the current study were primarily white (88.24\%) male (80.15\%) English-speakers with a mean age of $26.15(n=134)$. Additionally, the age range of participants spanned from 18 to 60. In contrast, the previous study focused only on 18 to 25-year-old college students in Taiwan [7]. Differences in societal values between collectivist and individualist cultures may have an impact on the relationships between motivations and both harmonious and obsessive passion. Second, although obsessive passion and addiction both target emotional dependence and negative effect, they are not synonymous. Obsessive passion measures feelings of compulsion and emotional dependence towards an activity, whereas the addiction ratings scale used by Shang et al. (2009) includes items that measure tolerance, withdrawal and relapse. The differences between the two constructs could account for the conflicting results.

The finding of the present study were similar to the findings of Fuster et al. (2014), which found positive relationships between HP and social, achievement, and exploration motivations, and positive relationships between OP and dissociation, social, and achievement motivations. For example, in the present study, competition was found to have a significant relationship with OP, which has both socialization and achievement characteristics. Although competition emphasizes winning and accomplishing tasks (achievement), it requires the active participation of other players in the context of an MMORPG (socialization). If competition is weakly related to OP, it follows that OP would be related to both socialization and achievement. OP was also found to have a weak relationship with challenge, which is related to the difficulty level of the game and the user's ability to overcome obstacles. Challenge could therefore be seen as a motivation that falls under the achievement dimension. Lastly, the motivations role-play and fantasy are similar to immersion, which was broken into two separate dimensions (exploration and dissociation) by Fuster et al. (2014).

Role-play is characterized by the relationship between users and the in-game avatars they have created. A high role-play score is related to how much users identify with their avatars, the amount of time they have invested in these creations, and 
whether or not the users feel as if they can achieve things that they cannot achieve in real life. This definition of role-play is similar to what other researchers have described as immersion and escapism. For example, Hagstrom and Kaldo (2014) noted that while escapism as a motivation can be broadly described as escaping reality, the term can also be used to mean "transcending reality" via being immersed in a fantasy world. In order to differentiate between the two meanings, researchers divided negative and positive escapism into separate categories. Fuster et al. (2014) similarly broke the motivational category of immersion into exploration and dissociation.

According to Hagstrom and Kaldo (2014), negative escapism is described as engaging in game-play to avoid unpleasant emotions or obligations in the user's life [15]. Similarly, Fuster et al. (2014) describes dissociation as an interpersonal motivation characterized by playing to avoid or escape reality. In contrast, exploration and positive escapism are both characterized as motivations that involve the user becoming immersed in the unique world of the game $[15,24]$. Although both negative escapism/positive escapism and dissociation/exploration involve 'escaping reality', positive escapism and exploration involve the addition of positive stimuli-for example, exploring an immersive and compelling fantasy world-whereas negative escapism and dissociation involve removing negative stimuli. The differences between dissociation and exploration could explain why, although role-play, curiosity, and fantasy are all strongly correlated with one another, only role-play and to a lesser extent fantasy correlate with obsessive passion.

Shang et al. (2009) divided the eleven motivational factors into social and personal dimensions, adding role-play as a third, separate category. However, the relationships between motivational factors become clearer if they are grouped together under social, achievement, and immersion dimensions. For example, role-play, fantasy, and curiosity have significant positive relationships with one another and are related to the immersion dimension by definition. Cooperation, belonging, recognition, and obligation all have significant positive relationships with each other and are related to the socialization dimension. Lastly, control, rewards, competition, and challenge are related to the achievement dimension and have significant relationships with one another, with the exception of control and rewards. The inter correlations between the motivations, in addition to their relationships with HP and OP, highlight the usefulness of using specific subcategories. For example, although competition and challenge were related to OP, other related motivations, such as recognition, control, and rewards, were not. If these motivations had been categorized as achievement and socialization, both would have been found to be related to OP. Additionally, if dimensions like achievement and socialization are too broad in scope, it can become difficult to interpret the results and limit our ability to identify potential risk factors for negative consequences associated with MMORPG playing. This is supported by researchers such Hagstrom \& Kaldo (2014) who noted that the escapism was a specific subcategory, and Fuster et al. (2014) who found significant differences in their results when they were able to identify subcategories within their previously identified motivational dimensions.

\section{Clinical Implications}

It has been well established that consideration of existential, spiritual and psychological needs is an important aspect of mental health care [26]. Past research, using a scale that measured relatedness, competence, and autonomy, found that need satisfaction (as measured by autonomy, competence, and relatedness) had a positive relationship with harmonious passion and a negative relationship with obsessive passion [23]. Interestingly, the basic needs measured (autonomy, competence, and relatedness) are similar to the psychological needs identified in Glasser's Choice Theory model. Similar to Maslow, Glasser postulates that all of our behaviors are actions taken in an effort to satisfy our basic needs $[27,28]$. The four psychological needs Glasser identifies are love and belonging, power and competence, freedom and autonomy, and fun and learning. Although humans all have the same psychological needs, the strength of each may vary from person to person. For example, one person may have a high need for power and a low need for freedom, while another person may have very low needs for power and freedom. By definition, these psychological needs are also similar to the motivations identified in the current study. The immersion dimension (exploration) relates to both freedom/autonomy and learning/fun, the social dimensions relate to love and belonging, and the achievement dimension relates to power.

If Glasser's psychological needs were applied to compulsive or obsessive MMORPG play, it could be theorized that gaming is being used to satisfy one of these basic needs in a way that is not being done in real life. Alternatively, players may engage in MMORPG use in order to avoid or dissociate from reality (where one of their psychological needs is not being met) in favor of a virtual world where their psychological need can be met. If this were true, it would be hypothesized that a high score in dissociation would indicate that a person's basic psychological needs were not being met.

Dissociation in this context would be similar to what a high score in obsessive passion would be indicating-that is, that positive feelings, self-esteem, social recognition and competence are contingent on the activity in question (i.e., MMORPG play). Although dissociation and obsessive passion might indicate that a problem exists, the next step would be to identify other motivations-more specifically, motivations that correlate with psychological needs - that a person is scoring highly on. For example, if a person has a high score in both dissociation and achievement motivations, although the dissociation may indicate problematic play, it may be more useful to focus on the client's achievement-oriented motivations for playing. If a person has a naturally high need for power or belonging that is not being met in the real world, it could be hypothesized that they may develop obsessive passion towards an activity (like MMORPG use) that satisfies this need [28].

It could be useful for future research to focus on this line of thinking, especially with regard to the development of treatment 
plans for clients who struggle with compulsive MMORPG use. In addition to focusing on ways to meet psychological needs in the real world instead of through the game, the emphasis on need satisfaction might provide a more helpful way to frame the problem to clients. The focus on need satisfaction may help people who were able to have healthy, harmoniously passionate relationships with MMORPG use in the past better understand the problem without labeling gaming as unhealthy overall.

\section{Limitations and Future Research}

There were several limitations to the present study. First, the majority of participants identified as white males, so the relationships between motivations and passion described may not be generalizable to other player populations. Since female participants accounted for only $19.85 \%$ of the population, it is difficult to draw any conclusions about gender differences in motivations. Past research on gender differences in motivation and passion in MMORPGs has found mixed results; it is recommended that future research focus on obtaining a larger female sample size and exploring whether or not motivation and passion interact different with regards to gender [27].

Next, participants were recruited through online MMORPG forums, which may also represent a selection bias. The majority of the forums that the survey was advertised in was subredditsonline forums that are a part of reddit, a large social networking community with numerous forums dedicated to different subjects-dedicated to individual MMORPGs. It is possible that players who frequent online gaming forums may be more invested in the social aspect of MMORPGs; players who are more competitive and invested in character optimization and strategy (achievement-oriented motivations) may also be more likely to frequent online forums. Future research should focus on identifying specific motivations that might be indicative of maladaptive behaviors and play style with regards to MMORPG users. Additionally, it would be beneficial to focus on motivational differences with a more diverse population in order to better generalize results. It might also be beneficial for future research to analyze the how correlations between different motivations and compulsive tendencies interact with each other.

\section{References}

1. Bean A, Groth-Marnat G. Video Gamers and Personality: A Five-Factor Model to Understand Game Playing Style. Psychology of Popular Media Culture. Advance online publication. 2014. DOI: 10.1037/ppm0000025

2. Blizzard EntertainmentWord of Warcraft(C) subscriber base reaches 12 million worldwide. 2010.

3. Cole H., Griffiths M. Social interactions in massively multiplayer online role-playing gamers. Cyberpsychology \& Behavior. 2007;10(4):575583. doi:10.1089/cpb.2007.9988

4. Ducheneaut N, Yee N, Nickell E, Moore R. J. "Alone together?" Exploring the social dynamics of massively multiplayer online games. ACM Conference on Human Factors in Computing Systems.2006. (CHI 2006); 2006 April 22-27; Montreal; Canada. NY: ACM. 2006;407-416. Doi:10.1145/1124772.1124834

5. Entertainment Software Association (ESA). Essential facts about the computer and video game industry.2012.
6. Fuster H., Chamarro A, Carbonell X, Vallerand R. J. Relationship between passion and motivation for gaming in players of massively multiplayer online role-playing games. Cyberpsychology, Behavior, and Social Networking.2014;17(5):292-297. DOI: 10.1089/cyber.2013.0349

7. Gabbiadini A., Mari S, Volpato C, Monaci M. G. Identification processes in online groups: Identity motives in the virtual realm of MMORPGs. Journal of Media Psychology: Theories, Methods, and Applications.2014;26(3):141-152. DOI: 10.1027/1864-1105/a000119

8. Glasser W. Counseling with choice theory: The new reality therapy. New York: HarperCollins.2001.

9. Graham L T, Gosling S D. Personality profiles associated with different motivations for playing World of Warcraft. CyberPsychology, Behavior, and Social Networking.2013;16(3):189-193. DOI: 10.1089/ cyber.2012.0090

10.Hagstrom D. Kaldo V. Escapism among players of MMORPGsConceptual clarification, its relation to mental health factors, and development of a new measure. Cyberpsychology, Behavior, and Social Networking.2014;17(1):19-25. DOI: 10.1089/cyber.2012.0222

11.Hussain Z, Griffiths M D, Baguley T. Online gaming addiction: Classification, prediction and associated risk factors. Addiction Research and Theory.2012;20(5):359-371. DOI: 10.3109/16066359.2011.640442

12.Kirby A., Jones C, Copello A. The impact of massively multiplayer online role playing games (MMORPGs) on psychological wellbeing and the role of play motivations and problematic use. International Journal of Mental Health and Addiction.2014; 12(1):36-51. DOI. 10.1007/ s11469-013-9467-9

13.Koslander T, da Silva A B, Roxberg A. Existential and Spiritual Needs in Mental Health Care. Journal of Holistic Nursing.2009;27(1):34-42. DOI: $10.1177 / 0898010108323302$

14.Kowert R., Oldmeadow J. (A) Social reputation: Exploring the relationship between online video game involvement and social competence. Computers in Human Behavior. 2013; 29(4):1872-1878. Doi:10.1016/j.chb.2013.03.003

15.Lafrenière M. A.K, Vallerand R.J, Donahue E G, Lavigne G L. On the costs and benefits of gaming: The role of passion. Cyber Psychology \& Behavior. 2009;12(3):285-290. DOI: 10.1089/cpb.2008.0234

16.Mehroof M, Griffiths M. Online gaming addiction: The role of sensation seeking, self-control, neuroticism, aggression, state anxiety, and trait anxiety. Cyberpsychology, Behavior, and Social Networking. 2010;13(3):313-316. doi:10.1089/cyber.2009.0229

17.Poels K., De Cock N, Malliet S. The female player does not exist: Gender identity relates to differences in player motivations and play styles. CyberPsychology, Behavior, and Social Networking,2012;15(11):634-638. DOI: 10.1089/cyber.2012.0164

18.Przybylski A K, Weinstein N, Ryan R., Rigby C S. Having to versus wanting to play: Background and consequences of harmonious versus obsessive engagement in video games. CyberPsychology and Behavior.2009;12(5):485-492. DOI: 10.1089/cpb.2009.0083

19.Shang H.H, Ming-Hui W, Muh-Cherng W. Exploring user experiences as predictors of MMORPG addiction. Computers \& Education.2009;53(3):990-999. Doi:10.1016/j.compedu.2009.05.016

20.Smahel D, Blinka L, Ledabyl O. Playing MMORPGs: Connections between addiction and identifying with a character. CyberPsychology and Behavior. 2008;11(6):715-718. DOI: 10.1089/cpb.2007.0210 
21.Smyth J M. Beyond self-selection in video game play: An experimental examination of the consequences of massively multiplayer online roleplaying game play. Cyberpsychology \& Behavior. 2007;10(5):717-727. doi:10.1089/cpb.2007.9963

22.Stoeber J, Harvey M, Ward J A, Childs J H. Passion, craving, and affect in online gaming: Predicting how gamers feel when playing and when prevented from playing. Personality and Individual Differences 2011;51(8):991-995. Doi:10.1016/j.paid.2011.08.006

23.Utz S, Jonas K J, Tonkens E. Effects of passion for massively multiplayer online role-playing games on interpersonal relationships. Journal of Media Psychology. 2012;24(2):77-86. DOI: 10.1027/1864-1105/ a000066

24.Vallerand R J. On the psychology of passion: In search of what makes people's lives most worth living. Canadian Psychology. 2008;49(1):113. DOI: 10.1037/0708-5591.49.1.1
25.Vallerand R J, Mageau G A, Ratelle C, Leonard M, Blanchard C, Koestner $\mathrm{R}$, et al. Les passions de l'ame: On obsessive and harmonious passion. Journal of Personality and Social Psychology. 2003;85(4):756-767. DOI: $10.1037 / 0022-3514.85 .4 .756$

26.Yee N. The demographics, motivations, and derived experiences of users of massively multi-user online graphical environments. Presence. 2006;15(3):309-329. Doi:10.1162/pres.15.3.309

27.https://www.sbp-journal.com/index.php/sbp/article/view/1627

28.Wang C K J, Khoo A, Liu W C, Divaharan S. Passion and intrinsic motivation in digital gaming. CyberPsychology \& Behavior. 2008; 11(1):39-45. DOI: 10.1089/cpb.2007.0004 